15th International Symposium on the Effects of Radiation on Matcrials Nashville, Tennessed, June $18 \cdot 21,1990$

R. E. Stoller', M. L. Grossbeck ${ }^{1}$, and L. K. Mansur ${ }^{2}$

DE91 000705

\title{
A THEORETICAL MODEL OF ACCELERATED IRRADIATION CREEP AT LOW TEMPERATURES BY TRANSIENTI INTERSTITIAL ABSORPTION
}

\section{DISCLAIMER}

This report was prepared as an account of work sponsored by an agency of the United States Government. Neither the United States Government nor any agency thereof, nor any of their employees, makes any warranty, express or implied, or assumes any legal liability or responsjbility for the accuracy, completeness, or usefulness of any information, apparatus, product, or process disclosed, or represents that its use would not infringe privately owned rights. Reference herein to any specific commercial product, process, or service by trade name, trademark, manufacturer, or otherwise does not necessarily constitute or imply its endorsement, recommendation, or favoring by the United States Government or any agency thereof. The views and opinions of authors expressed herein do not necessarily state or reflect those of the United States Government or any agency thereof.

${ }^{1}$ Research siaff members and ${ }^{2}$ group leader Metals and Ceramics Division Oak Ridge National Laboratory P.O. Box 2008

Oak Ridge, TN 37831-6376 (USA)

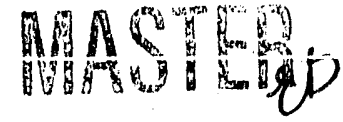




\title{
A THEORETICAL. MODEL OF ACCELERATED IRRADIATION CREEP AT LOW TEMPERATURES BY TRANSIENT INTERSTITIAL ABSORPTION*
}

\author{
R. E. Stoller, M. L. Grossbeck, and L. K. Mansur \\ Metals and Ceramics Division, Oak Ridge National Laboratory, \\ P.O.Box 2008, Oak Ridge, TN 37831-6376 (USA)
}

\begin{abstract}
A theoretical model has been developed using the reaction rate theory of radiation effects to explain experimental results that showed higher than expected values of irradiation creep at low temperatures in the Oak Ridge Research Reactor (ORR). The customary assumption that the point defect concentrations are at steady state was not made; rather, the time dependence of the vacancy and interstitial concentrations and the creep rate were explicitly calculated. For temperatures below about 100 to $200^{\circ} \mathrm{C}$, the time required for the vacancy concentration to reach steady state exceeds the duration of the experiment. For example, if materials parameters typical of austenitic stainless steel are used, the calculated vacancy transient dose at $100^{\circ} \mathrm{C}$ is about 100 dpa. At $550^{\circ} \mathrm{C}$ this transient is over by $10^{-8}$ dpa. During the time that the vacancy population remains lower than its steady state value, dislocation climb is increased since defects of primarily one type (interstitials) are being absorbed. Using the time-dependent point defect concentrations, the dislocation climb velocity has been calculated as a function of time and a climb-enabled glide creep model has been invoked. The extended transient time for the vacancies leads to high creep rates at low temperatures. In agreement with the experimental observations, a minimum in the temperature dependence of creep is predicted at a temperature between 50 and $350^{\circ} \mathrm{C}$. The temperature at which the minimum occurs decreases as the irradiation dose increases. Predicted values of creep at $8 \mathrm{dpa}$ are in good agreement with the results of the ORR-MFE- $6 \mathrm{~J} / 7 \mathrm{~J}$ cxperiment.
\end{abstract}

KEY WORDS: creep, dislocation climb, dislocation glide, fusion, irradiation creep, point defects, theoretical models, transient effects

\footnotetext{
Encrgy, under contract DE-AC05-840R21400 with Martin Marictta Energy Systems, Inc.

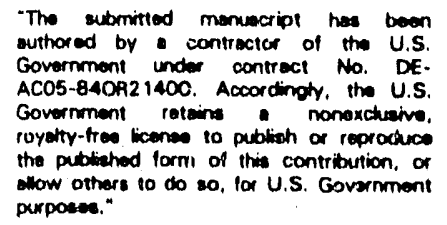

* Research sponsored by the Division of Materials Sciences and the Office of Fusion Energy, U.S. Department of 
The phenomenon of irradiation creep has been studied extensively for more than thirty years. Early work in this lield was discussed by Gittus in 1975 [1], and several recent reviews provide an overview of what are helieved to be the primary mechanisms responsible for irradiation creep [2-7]. One of the principal experimental observations regarding irradiation creep in austenitic stainless steels is that it is relatively insensitive to temperature between about $3(0)$ to $6000^{\circ} \mathrm{C}[8,9]$. Above $6010^{\circ} \mathrm{C}$, thermal creep increases rapidly and dominates the creep behavior. Irradiation creep has not been a major conecrn at temperatures below about $300^{\circ} \mathrm{C}$ because few reactor components operating at these temperatures are exposed to a high neutron llux. However, low temperature irradiation creep was reported as early as 1967 by Hesketh [10] and discussed by Gilbert in 1971 [11].

Recent interest in lower operating temperatures for near-term fusion reactor components led to the design of an experiment to investigate irradiation creep at temperatures as low as $60^{\circ} \mathrm{C}$ [12]. The experiment also involved the use of neutron spectral tailoring to achieve nearly the fusion helium to dpa ratio [13]. Pressurized tubes were used to achicve hoop stresses from 50 to $400 \mathrm{MPa}$. The irradiations were conducted at temiperatures of $60,200,330$, and $400^{\circ} \mathrm{C}$. The capsule containing the lower two temperatures was designated ORR-MFE-6J and reached a maximum dose of $6.9 \mathrm{dpa}$. The specimens irradiated at 330 and $40\left(0^{\circ} \mathrm{C}\right.$ reached an estimated $8 \mathrm{dpa}$ in a capsule designated ORR-MFE-7J. Helium generation was in the range of 9 to 12 appm/dpa. Additional experimental details for the ORR-MFE-6J and $7 \mathrm{~J}$ are given elsewhere $[12,13]$.

\section{CREEP MEASUREMENTS FROM ORR-MFE-6J AND 7J}

Irradiation creep of the pressurized tubes was determined by measuring the average diameter change in the central region of the tubes. A noncontacting laser micrometer system was used [12]. Values of the effective uniaxial irradiation creep strain measured in a $25 \%$ coldworked austenitic stainless steel designated PCA are shown for several temperatures as a function of the effective uniaxial stress in Fig. 1. PCA is the U.S. fusion materials program's Prime Candidate Alloy. Similar results were obtained for other austenitic alloys irradiated in this experiment in both the solution annealed and cold-worked conditions [12]. For pressurized tubes, the effective uniaxial stress is 0.87 times the hoop stress and the effective uniaxial strain is 1.33 times the diametral strain [14].

The feature of the data shown in Fig. 1 that is of most interest here is that the irradiation creep measured at $60^{\circ} \mathrm{C}$ is greater than that observed at the higher temperatures. The measured creep strains are shown as a function of temperature in Fig. 2 to emphasize this point. The results of the ORR-MFE- $6 \mathrm{~J} / 7 \mathrm{~J}$ indicate that there is a minimum in the creep curve at a temperature of about $200^{\circ} \mathrm{C}$ for a total dose of 7 to 8 dpa. Unfortunately, no information can be obtained on the dose-depencience of creep at these temperatures because the experiment was terminated at this dose.

\section{CREEP DUE TO TRANSIENT INTERSTITIAL ABSORPTION}

The high values of irradiation creep observed at low temperatures in the ORR-MFE-6J/7J experiment have been discussed in an carlier publication. A new mechanism was proposed to account for the results [12]. The mechanism was enhanced dislocation climb due to unbalanced interstitial absorption. Since the interstitial is much more mobile than the vacancy, the interstitial 
concentration reaches its steady state value more quickly than does the vacancy concentration. Therefore, during the time required for the vacancy concentration to reach steady state, dislocations (and other sinks) primarily absorb interstitials. This unbalanced absorption of one defect type leads to accelerated dislocation climb, which leads to increased glide and ultimately, higher crecp rates.

In order to investigate the potential influence of this transient interstitial absorption, the point defect transient was separated into four conceptually distinct regions [12]. Approximations were made to obtain values for the point defect concentrations in each region, and to calculate the subsequent dislocation climb and glide as a function of the irradiation temperature. Their results indicated that the point defect transient could give rise to significant creep below about $3000^{\circ} \mathrm{C}$. Similar levels of creep were obtained at 100 and $300^{\circ} \mathrm{C}$, with a maximum in the creep curve near $200^{\circ} \mathrm{C}$.

The model discussed here removes the approximations used in Ref. 12. The rate equations for the print defect concentrations and the creep rate due to the climb-enabled glide mechanism were numerically integrated to obtain values for irradiation creep as a function of dose and temperature. Before turning to the creep model, the behavior of the point defect concentrations will be briefly reviewed.

Time-dependence of Point Defect Concentrations

The rate equations that describe the interstitial (subscripi-i) and vacancy (subscript-v) concentrations can be written as:

$$
\begin{aligned}
& \frac{d C_{i}}{d t}=G_{i}-P C_{i} C_{v}-D_{j} C_{i} \sum_{j} S_{v}^{j} \\
& \frac{d C_{v}}{d t}=G_{v}-R C_{i} C_{v}-D_{v} C_{v} \sum_{j} S_{v}^{j}
\end{aligned}
$$

where $\mathrm{C}$ is the concentration, $\mathrm{D}$ is the diffusivity, $\mathrm{G}$ is the generation rate. The constant $\mathrm{R}$ in Eqs. (1) and (2) is the recombination coefficient, and the $S^{j}$ are the sink strengths for the various extended defects (eg. dislocations, grain boundaries, and cavities). The point defect generation rates in these equations reflect the influence of in-cascade recombination and clustering and thermal vacancy emission from sinks. More detailed information about the various terms in Eqs. (1) and (2) is given in Refs. 15 to 17.

The time required for the point defect concentrations to reach steady state is determined by the displacement rate and the sink structure. The commonly-used steady state approximations to the point defect concentrations are obtained by setting the time derivatives in Eqs. (1) and (2) equal to zero and solving these two equations simultaneously. However, this approximation is invalid if the experiment of interest is short compared to the time (or dose) required to reach 
steady state. Three characteristic times can be defined that describe the approach to steady state [15]. The relative importance of these three times is determined by the maljor point defect loss mechanism. In principle, point defect loss can be dominated by either mutual recombination or absorption at sinks. A mixed or intermediate case between these two cxtremes is also possible. All three cases are illustrated in Fig. 3, where the three characteristic times have been converted to doses by multiplying each time by the displacement rate $\left(G_{d p a}\right)$, i.e., $\Delta_{j}=G_{d p a t} \tau_{j}$. The values of the point defect concentrations shown in Fig. 3 were calculated by integrating Eqs. (1) and (2) with the material and irradiation parameters listed in Table 1 . These values are representative of austenitic stainless steels. However, the relevant results of these calculations are not sensitive to rather large changes in these basic parameters.

The first time (dose) to note in Fig. 3 is thit required for the defect concentrations to rench a high enough value for mutual recombination to limit their further increase, $\tau_{R}$. If the point defects are lost only to recombination, then $\tau_{\mathrm{R}}$ also determines the time to steady state.

$$
\tau_{R}=\left(R G_{i}\right)^{-\frac{1}{2}}
$$

If there is a significant loss of point defects to sinks (as is usually the case), then the time required for the vacancies to diffuse to $\operatorname{sir} s, \tau_{v}$, is the time that defines the approach to steady state,

$$
\tau_{v}=\left(D_{v} \sum_{j} S_{v}^{j}\right)^{-1}
$$

In this case $\tau_{R}$ determines the time required to reach a pseudo-steady state as shown in Fig 3 . The time for interstitials to diffuse 10 sinks, $\tau_{i}$, is typically much shorter than $\tau_{v}$ because of the higher interstitial diffusivity,

$$
\tau_{i}=\left(D_{i} \sum_{j} S_{i}^{J}\right)^{-1}
$$

In order to show the behavior at the sink and recombination dominated limits in Fig. 3, somewhat extreme values of the dislocation sink strength were used, $10^{16} \mathrm{~m}^{-2}$ for the sink dominated case denoted by "s" and essentially zero for the recombination dominated case denoteci by " $r$ ". A value of $10^{10} \mathrm{~m}^{-2}$ was used for the intermediate case denoted by " $\mathrm{m}$ ". In each of the three cases, the point defect concentrations initially build up linearly. For the recombination dominated case the point defect concentrations reach steady state at $\Delta_{R}$. For the sink dominated case, $\Delta_{\mathrm{i}}(\mathrm{s})<\Delta_{\mathrm{R}}$ and the interstitial and vacancy concentrations directly build up to their steady state values at $\Delta_{i}(\mathrm{~s})$ and $\Delta_{\mathrm{v}}(\mathrm{s})$, respectively. For the intermediate case, $\Delta_{\mathrm{i}}(\mathrm{m})>\Delta_{\mathrm{R}}$ and the point defect concentrations follow the same behavior as recombination dominant until the interstitials begin to be lost to sinks at $\Delta_{\mathrm{i}}$. The interstitial concentration decreases and the vacancy concentration increases until vacancies begin to be lost to sinks and steady state is reached at $\Delta_{\mathrm{v}}(\mathrm{m})$. 
The temperature dependence of the time, $\tau_{v}$ required for the vacancy concentration to reach steady state is shown in Fig. 4 using microstructural and material parameters from Table 1. This time is about 1 hour at $2500^{\circ} \mathrm{C}$ and increases rapidly at lower temperatures. At $1000^{\circ} \mathrm{C}$, the time is about 6 years. This indicates that the steady state point defect concentrations would never be reached during low-temperature irradiation experiments. Even for somewhat higher temperatures, the effect of multiple reactor start-up and shutdown cycles could prevent steady state from being achicved.

\section{Influence of Point Deiect Transient on Dislocation Motion}

During the extended point defect transient, dislocations will absorb an excess of interstitials leading to enhanced climb in one direction. The dislocation climb velocity can be calculated as:

$$
v_{d}^{c 1}=\frac{1}{b_{d}} \frac{2 \pi}{\ln \left(r_{0} / r_{c}\right)}\left[Z_{i}^{d} D_{i} C_{i}-Z_{v}^{d} D_{v}\left(C_{v}-C_{v}^{d}\right)\right]
$$

where $b_{d}$ is the Burgers vector, $Z_{t}^{d}$ and $Z_{v}{ }^{d}$ are the dislocation capture efficiencies and $C_{v}{ }_{v}$ is the vacancy concentration in equilibrium with the dislocation [17]. The constants $r_{o}$ and $r_{c}$ in Eq. (6) are the inner and outer cutoff radii used in calculating the dislocation sink strength $[16,17]$.

The point defect concentrations and the dislocation climb velocity at 100 and $500^{\circ} \mathrm{C}$ are shown as a funcion of dose in Fig. $5 \mathrm{a}$ and $5 \mathrm{~b}$. Over this temperature range, the duration of the point defect transient varies by almost nine orders of magnitude. The influence of the duration of the point defect transient can be clearly seen in Fig. 5b. At very low doses, the climb velocity is higher at $500^{\circ} \mathrm{C}$ than at $100^{\circ} \mathrm{C}$ due to the higher defect mobility. However, as the point defect concentrations approach steady state at $500^{\circ} \mathrm{C}$ near $10^{-7} \mathrm{dpa}$, the climb velocity at $100^{\circ} \mathrm{C}$ exceeds that at $500^{\circ} \mathrm{C}$. It remains greater from about $2 \times 10^{-7} \mathrm{dpa}$ to $5 \mathrm{dpa}$. The climb velocity in Fig. $5 \mathrm{~b}$ was calculated using the parameters listed in Table 1 . These point defect capture efficiencies neglect any effects of stress-induced preferential interstitial absorption. These effects will be discussed below.

\section{Predicted Irradiation Creep}

The irradiation creep mechanism that has been chosen to investigate the influence of this accelcratud dislocation climb is that of climb-enabled dislocation glide. This mechanism has been described by Mansur [18], and leads to the following equation for the creep rate:

$$
\frac{d e}{d t}=\frac{\sigma}{E}\left(\pi p_{d}\right)^{1 / 2} v_{d}^{c l}
$$

where $\sigma$ is the applied stress, $E$ is Young's modulus and $\rho_{d}$ is the dislocation density. If the effect of preferential interstitial absorption [19-21] is included in the dislocation climb velocity, Mansur has shown that the creep rate due to climb-enabled glide is comparable to that calculated for the conventional stress-induced preferential absorption (SIPA) mechanism for stresses near $100 \mathrm{MPa}$ [18]. These creep rates are generally smaller than those due to the transient interstitial absorption 
mechanism which is the subject ol the present paper. In order to oblain the results that ate discussed below, the point defect capture efficiencies of Wolfer and Ashkin [20) were adopted. The dislocation densities discussed in Ref. 12 were used to permit the direct comparison of the carlier, simplified calculations with the present work.

The predicted values of irradiation creep at $50,100,300)$, and $5(6)^{\circ} \mathrm{C}$ are shown as a function of dose in Fig. 6. The general hehavior can be most clearly seen in the eurve for $3(0) 0^{\circ} \mathrm{C}$. In this case, the point defect transient leads 10 a high ereep rate up to about $10^{-4}$ dpa. The creep rate then drops to near zero as the point defeets approach their steady state values. At about $10^{-2}$ dpa, the creep rate begins to increase due to the steady state climb-glide mechanism driven by SIPA. The behavior is similar at the other temperatures, but only part of the behavior can be observed in the dose increment included in Fig. 6. At $5000^{\circ} \mathrm{C}$, the steady state creep rate is somewhat higher, but the transient is very short and contributes little to the accumulated creep. At 50 and $100^{\circ} \mathrm{C}$, the transient dominates the creep behavior. In Fig. 6, the transient has just ended at near $100 \mathrm{dpa}$ for $100^{\circ} \mathrm{C}$ irradiation, while the transient extends beyond 1000 dpa at $50^{\circ} \mathrm{C}$.

Once steady state creep has been established, the expected temperature dependence of creep is observed. The predicted creep is only weakly dependent on temperature until a temperature is reached where thermal crecp processes begin to be significant. Prior to this time, the temperature dependence is more complex. This temperature dependence is shown in Fig. 7 at four doses for an applied stress of $100 \mathrm{MPa}$. At the lowest temperatures, irradiation creep due to the point defect transient always dominates the behavior for the doses shown in Fig. 7. At the high temperatures, the accumulated creep is due to the transient at low doses but due to steady state creep at the higher doses. At low doses, prior to the accumulation of significant steady state creep, greater creep is predicted at the low temperatures. However, the higher steady state creep rates predicted above $300^{\circ} \mathrm{C}$ lead to comparable values of irradiation creep at these temperatures for doses greater than about $10 \mathrm{dpa}$. Since the creep rate is higher at steady state than it is during the transient, the total creep increases faster at the higher temperatures. This behavior leads to a minimum in the creep curve near $200^{\circ} \mathrm{C}$ at intermediate doses. The minimum moves to lower temperatures as the dose increases because the temperature range of significant steady state creep extends to lower temperatures at higher doses. This result highlights a major difference between the present work and that reported in Ref. 12. In that work, essentially the same creep model was used as presented here. However, the use of piece-wise approximations for the actual time-dependent values of the point defect concentrations and summation rather than numerical integration, led to a maximum in the creep curve at $200^{\circ} \mathrm{C}$.

The creep measured in $25 \%$ cold-worked PCA after irradiation to 8 dpa in the ORR-MFE-6J/7J experiment at an effective stress of $90 \mathrm{MPa}$ is also shown in Fig. 7. The values of irradiation creep predicted by the model described here compare very favorably with these measurements. In particular, good agreement is shown between the measured and predicted creep at $60^{\circ} \mathrm{C}$ where steady state creep models fail to predict significant creep. A comparison of the predicted values in Fig. 7 and the data in Fig. 2 also shows good qualitative agreement.

The predictions of models such as that used here are known to be sensitive to the microstructural and material parameters that are used. However, all parameters used here are within the range of those thought to be appropriate for austenitic stainless stecls. In addition, the predictions of the model have bien examined to determine their sensitivity to reasonable parameter variations. Two examples of this parametric analysis are shown in Fig. 8 where the solid curves in Figs. 8a and 8 b are the predictions with the base parameter set discussed above. 
The inlluence of the assumed dislocation capture efliciencies for point defects is shown in Fig. Bil. If preferential ahsorption is neglected, and the capture efficiencies listed in Table 1 are used, the broken curve is obtained. Much less creep is predicted at intermediate temperatures due to the absence of SIPA. However, the point defect transient-induced creep persists at low temperatures and thermal e1 ep contributes above about $5(2))^{\circ} \mathrm{C}$. The influenee of the vacancy migration energy is showe in Fig. 8b. Here again, the basic behavior is not altered in a significant way. Both the minimum in the creep curve and the temperature at which thermal ereep begins to oceur are decreased as a result of higher vacancy mobility.

\section{SUMMARY AND DISCUSSION}

At low temperatures, the time required for the point defect eoneentrations to reach steady state can exeee? 1000 dpa. The influence of this lengthy transient on irradiation creep has been examined using a climb-cnabled glide creep model. The transient has been shown to lead to enhanced creep at temperatures below about $250^{\circ} \mathrm{C}$. A comparison between the model's predictions and irradiation creep data in the range of $6010400^{\circ} \mathrm{C}$ from the ORR-MFE-6J/7J experiment shows good agreement and supports the conclusion that the point defect transient is responsible for the low-temperature creep observed in this experiment.

This mechanism of irradiation creep is similar to that discussed by MacEwen and Fidleris [22]. They were concerned about creep in Zircaloy reactor components due to the point defect transients induced by the multiple start-up and shutdown cycles experienced by commercial reactors. Although the point defect transient is relatively short at the temperatures used in their experiments $\left(300-335^{\circ} \mathrm{C}\right)$, they were able to show a correlation between the creep rate and the point defect transient. Simonen and Hendrick [23] explored a related effect when they investigated the influence of pulsed irradiation on irradiation creep. They found that the creep rate in nickel at $200^{\circ} \mathrm{C}$ under pulsed irradiation was about three times that under steady irradiation and attributed the increase to uncompensated interstitial absorption during the pulse on-time and uncompensated vacancy absorption during the pulse off-time [23].

Any microstructural evolution that is determined by the ret flux of point defects (interstitials minus vacancies) should be similarly enhanced at low temperatures. Thus, the implications of this work extend to other radiation-induced property changes as well. For example, although it was not investigated here, the high interstitial supersaturation that is obtained during the transient should lead to enhanced formation of interstitial clusters. Since these clusters are nuclei for interstitial loops, the point defect transient could cause unexpected hardening at these irraciation conditions. Similarly, the rapid xecovery of the dislocation network and the high interstitial loop densities that are sometimes observed at low temperatures and doses could be explained by this effect.

Taken together with the earlier work discussed above $[12,22,2.3]$, these results indicate the need for a careful determination of the expected behavior of irradiated materials at low temperatures. The steady state rate equations can not be used to model such behavior. Rather, more detailed models should be developed that explicitly follow the time dependence of the point defects, point defect clusters, and the other extended defects present in the microstructure. Fortunately, recent advances in computing hardware will permit such calculations to be done at relatively low cost. 


\section{References}

1. J. H. Giltus, Crecp, Viscoclasticity and Creep Fracture in Solids, John Wilcy and Sons, New York, 1975.

2. W. A. Coghlan, International Metals Reviews 31 (1986) 245-257.

3. V. V. Slyozov and P. A. Bereznyak, "Irradiation Creep in Mctals," in Physics of Radiation Effects in Crystals, R. A. Johnson and A. N. Orlov, Eds., Elsevier Science Publishers, Amsterdam, 1986, pp. 576-620.

4. C. Wassilew, K. Ehrlich and H. J. Bergmann, "Analysis of the In-Reactor Creep and Crecp-Rupture Life Behavior of Stabilized Stainless Stecls and the NickelBase Alloy Hastelloy-X," Influence of Radiation on Material Properties, Proc. of 13th International Symposium, ASTM STP 956, F. A. Garner, C. H. Henager, and N. Igata, Eds., Amcrican Socicty for Testing and Matcrials, Philadelphia, 1987, pp. 30-53.

5. F. A. Garner and D. S. Gelles, J. Nucl. Mater. 159 (1988) 286-309.

6. E. P. Simonen, Met. Trans. 21A (1990) 1053-1063.

7. L. K. Mansur, "Kinetics of Irradiation Creep Based on Defect Reactions," in Irradiation Creep, E. P. Simonen, Ed., Trans Tech Publications, Lid., Acdermanndorf, Switzerland, in press.

8. M. L. Grossbeck and J. A. Horak, J. Nucl. Mater. 155-157 (1988) 1001-1005.

9. E. R. Gilbert, J. L. Straalsund, and G. L. Wire, J. Nucl. Mater. 65 (1977) 266-278.

10. R. V. Hesketh, "Collapse of Vacancy Clusters to Dislocation Loops," in Proc. of. Int. Conf. on Solid State Physics Research with Accelerators, BNL-50083, September 25 to 28, 1967, A. N. Goland, Ed., Brookhaven National Laboratory, Upton, NY, pp. 389-401.

11. E. R. Gilbert, Reactor Technology 14 (1971) 258-285.

12. M. L. Grossbeck, L. K. Mansur and M. P. Tanaka, "Irradiation Creep in Austenitic Stainless Stecls at 60 to $400^{\circ} \mathrm{C}$ with a Fusion Reactor Hclium to dpa Ratio," Effects of Radiation on Matcrials, Proc, of 14th International Symposium, ASTM STP 956, N. H. Packan, R. E. Stoller, and A. S. Kumar, Eds., American Society for Testing and Matcrials, Philadelphia, 1990, pp. 537-550.

13. J. A. Conlin and J. W. Woods, "Irradiation Experiments for the U.S./Japan Collaborative Testing Program in the HFIR and ORR." Alloy Development for Irradiation Performance, Semiannual Progress Report for Period ending March 31, 1984, DOE/ER-0045/12, Oak Ridge National Laboratory, Oak Ridge, TN, July, 1984 , p. 37.

14. E. R. Gilbert and L. D. Blackburn, J. of Eng, Mat. and Tech. 99 (1.977) 168-180. 
15. L. K. Mansur, Nucl. Tech. 40 (1978) 5-34.

16. A. D. Brailsford and R. Bullough, "The Theory of Sink Strengths," AERE Harwell Report TP.854, AERE Harwell, UK, 1980 .

17. R. E. Stoller and G. R. Odette, "A Composite Model of Microstructural Evolution in Austenitic Stainless Steel Under Fast Neutron Irradiation," Radiation-Indueed Changes in Microstructure, Proc. of 13 th International Symposium, ASTM STP 955, F. A. Garner, N, H. Packan and A. S. Kumar, Eds., American Socicty of Testing and Materials, Philadelphia, 1987, pp. $371-392$.

18. L. K. Mansur, Phil. Mag. A 39 (1979) 497-506.

19. P. T. Heald and M. V. Speight, Phil. Mag. 29 (1974) 1075-1080.

20. W. G. Wolfer and M. Ashkin, J. Appl. Phys. 47 (1976) 791-800.

21. W. G. Wolfer, L. K. Mansur, and J. Sprague, "Theory of Swelling and Irradiation Creep," Radiation Effects on Brecder Reactor Structural Materials, Proc. of Int. Conf, M. L. Bleiberg and J. W. Bennett, Eds., American Institute of Mining, Metallurgical and Petroleum Engineers, New York, 1977, pp. 841-864.

22. S. R. MacEwen and V. Fidleris, Phil Mag. 31 (1975) 1149-1157.

23. E. P. Simonen and P. L. Hendrick, J. Nucl. Mater. 85 \& 86 (1979) 973-876. 
Table 1. Typical Matcrial Parameters

$\begin{array}{ll}\text { Interstitial migralion encrgy (cV) } & 0.15\end{array}$

Vacancy migration encrgy (cV) $\quad 1.4$

Vacancy formation energy (eV) $\quad 1.6$

$\begin{array}{ll}\text { Recombination radius ( } \mathrm{nm}) & 0.25\end{array}$

$\begin{array}{ll}\text { Surface free energy }\left(\mathrm{J} / \mathrm{m}^{2}\right) & 1.50\end{array}$

Interstitial-dislocation capture efficiency, without $\quad 1.25$

preferential absorption

with preferential absorption $\quad \sec [20]$

Vacancy-dislocation capture efficiency,

$\begin{array}{ll}\text { without preterenatial absorption } & 1.00\end{array}$

with preferential absorption $\quad$ sec [20]

Displacement rate $(\mathrm{d} p \mathrm{p} / \mathrm{s}) \quad 1.0 \times 10^{-6}$ 
Figure Captions

Figure 1. Stress dependence of irradiation creep measured in $25 \%$ cold-worked PCA after irradiation to $6.9(60)$ and $2(10)^{\circ} \mathrm{C}$ ) and $\left.8.0(3.30 \text { and } 4(0))^{\circ} \mathrm{C}\right)$ dpa in the ORR-MFE-6J/7J experiment.

Pigure 2. Temperature dependence of irradiation creep at 87 and $193 \mathrm{MPa}$ measured in $25 \%$ cold-worked PCA after irradiation to $6.9(60 \text { and } 200)^{\circ} \mathrm{C}$ ) and 8.0 $\left(330\right.$ and $\left.400^{\circ} \mathrm{C}\right)$ dpa in the ORR-MFE-6J/7J experiment.

Figure 3. Dose dependence of the interstitial and vacancy concentrations for recombination-dominanted defect absorption ( $r$-Low Sink Strength), sinkdominated defect absorption (s-High Sink Strength), and an intermediate case (m-Mixed). Sce text for sink strength values.

Figure 4. Temperature dependence of the the time required for the vacancy concentration to reach stcady state (Eq. 5) for parameters typical of austenitic stainless steel.

Figure 5. Dose dependence of the point defeet concentrations (a) and the dislocation climb velocity (b) at 100 and $500^{\circ} \mathrm{C}$.

Figure 6. Predicted values of irradiation creep due to the climb-assisted dislocation glide mechanism. Results are shown as a function of dose with an applied stress of $100 \mathrm{MPa}$ for irradiation temperatures of $50,100,300$, and $500^{\circ} \mathrm{C}$.

Figure 7. Temperature dependence of the predicted values of irradiation creep due to the climb-assisted dislocation glide mechanism. Results are shown for four doses with an applied stress of $100 \mathrm{MPa}$ and compared with measurements of $25 \%$ cold-worked PCA irradiated in the ORR-MFE-6J/7J experiment.

Figure 8. Dependence of the predicied irradiation creep at 8 dpa on model parameters. The solid lines in (a) and (b) indicate the behavior with base parancter set discussed in the text. The broken line in (a) shows the predicted behavior if stress-induced preferential interstitial absorption is not included in the model and the effect of varying the vacancy migration energy is shown in (b). 


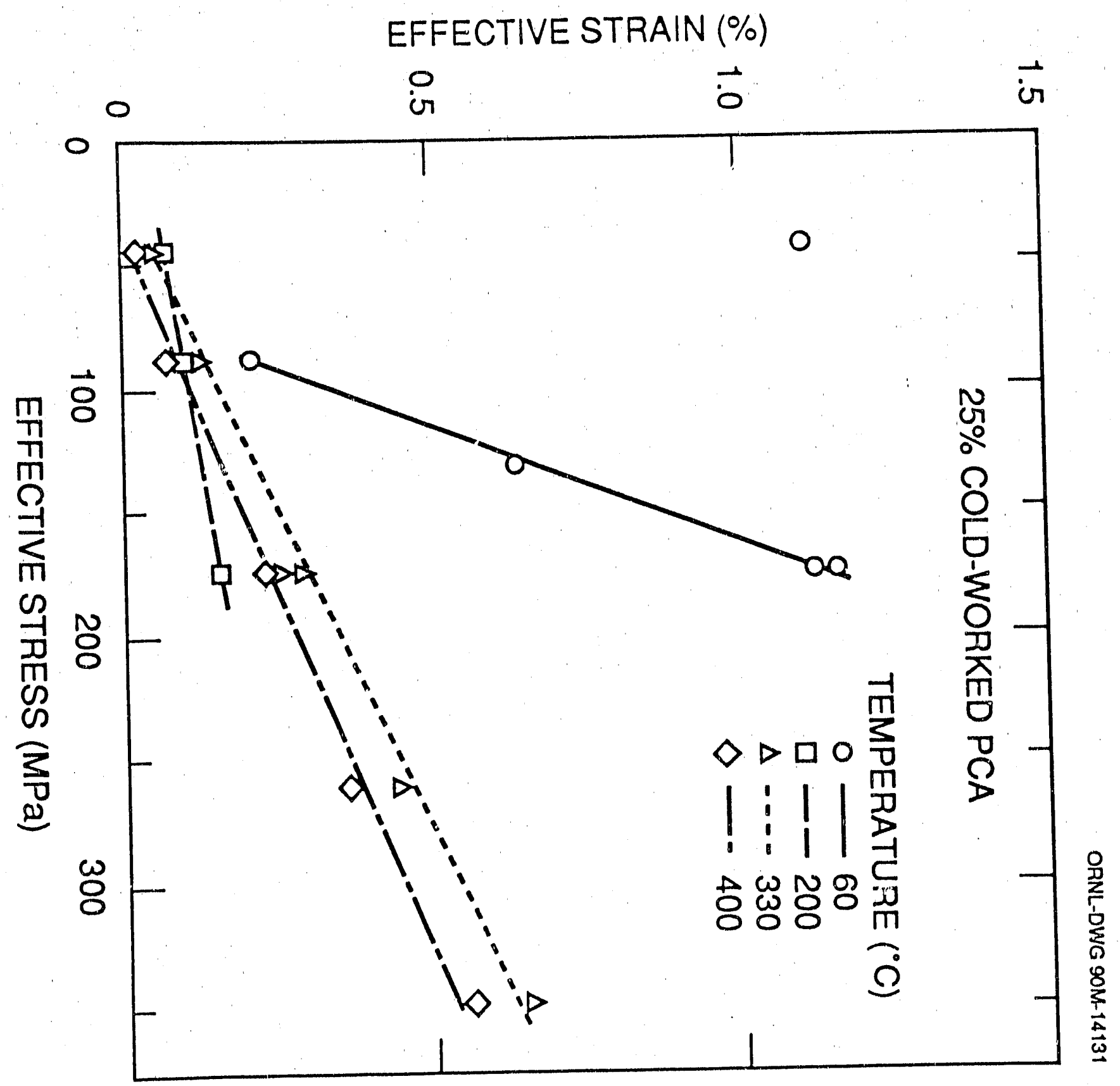

Figure i. Siress depencience of irradiation creep measured in $25 \%$ coid-worked PCAA after irradiation to $6.9(60$ and $200 \mathrm{C})$ and $8.0(330$ and $400 \mathrm{C}) \mathrm{dpa}$ in the ORR-MFE-6J/7J experiment.

(Stoller, Grossbeck and Mansur) 


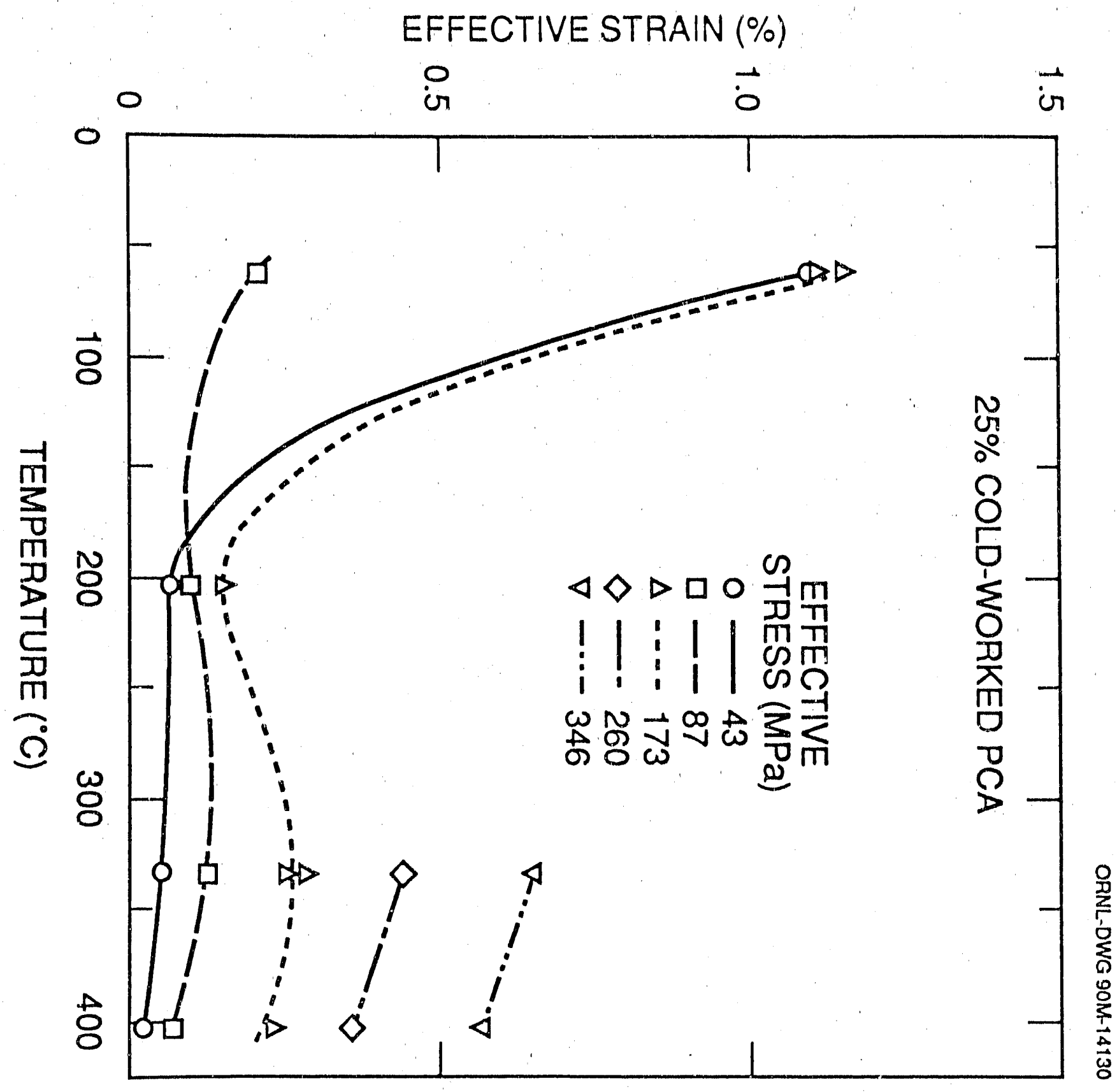

Figure 2. Temperature dependence of irradiation creep at 87 and $193 \mathrm{MPa}$ measured in $25 \%$ cold-worked PCA after irradiation to $6.9(60$ and $200 \mathrm{C})$ and 8.0 (330 and $400 \mathrm{C}$ ) dpa in the ORP-MFE-6.J/7J experiment.

(Stoller, Grossbeck and Mansur) 
FRACTIONAL VACANCY, $C_{V}$ OR INTERSTITIAL, $C_{i}$ CONCENTRATION (nUmber per atom)

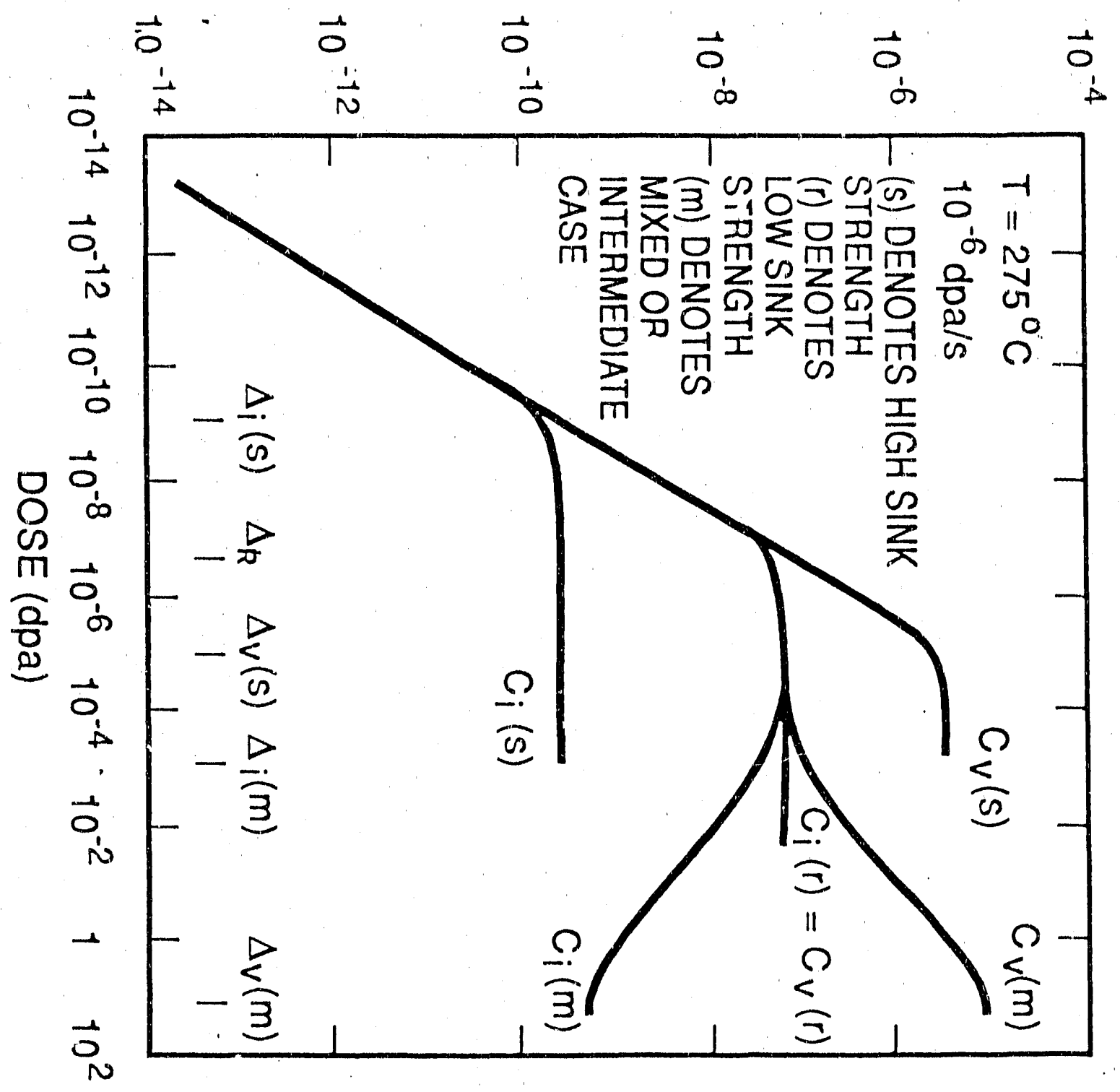

Figure 3. Dose dependence of the interstitial and vacancy concentrations for sink-dominated defect absorption (s-High Sink Sow Sink Strength). intermediate case (m-Mixed). See text fink Strength), and an (Stoller, Grossbeck and Mansur) 


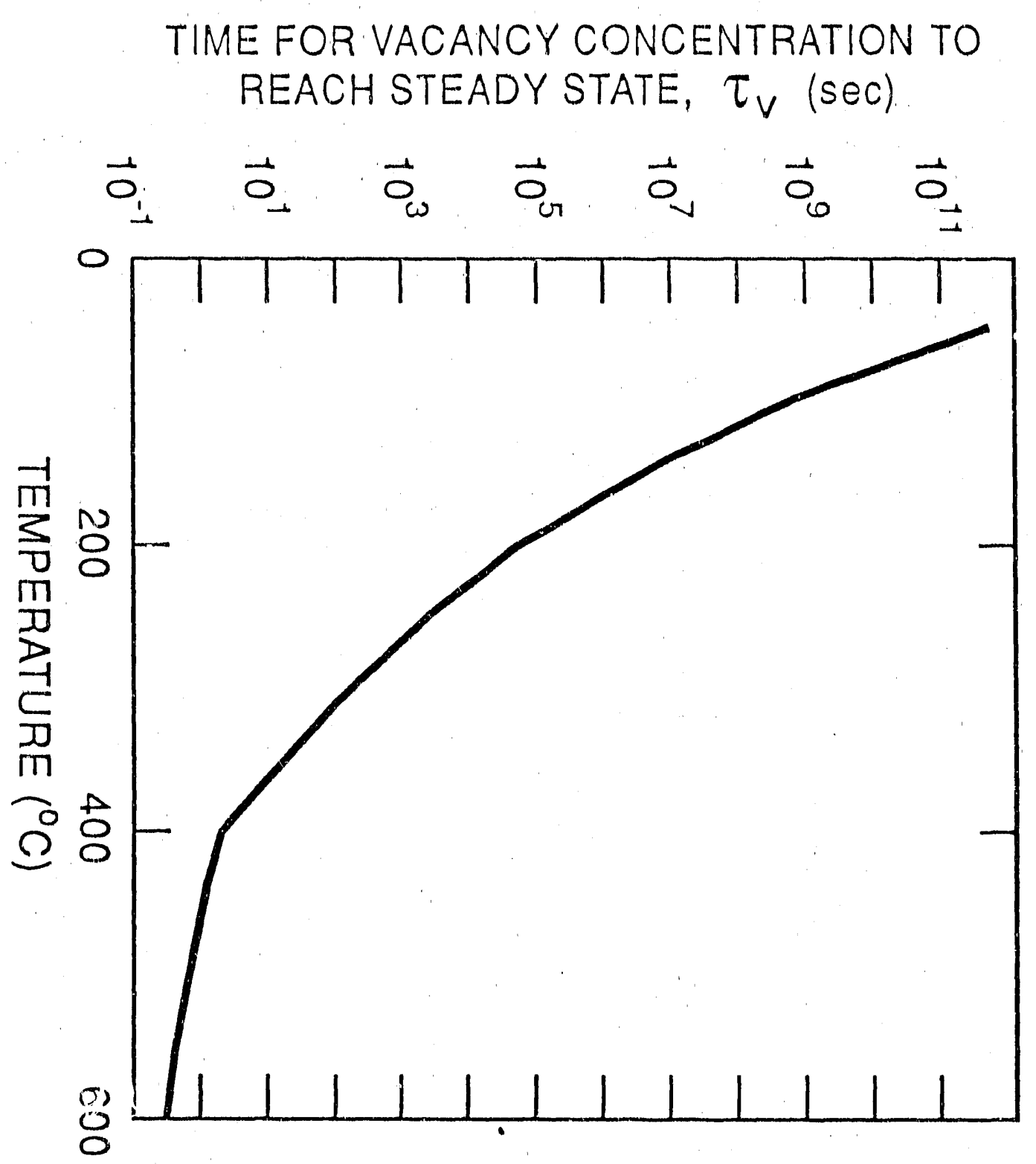

Figure 4. Temperature dependence of the the time required for the vacancy concentration to reach steady state ( $\mathrm{Eq} .5$ ) for parameters typical
of austenitic. stairiless steel.

(Stoller, Grossbeck and Mansur) 


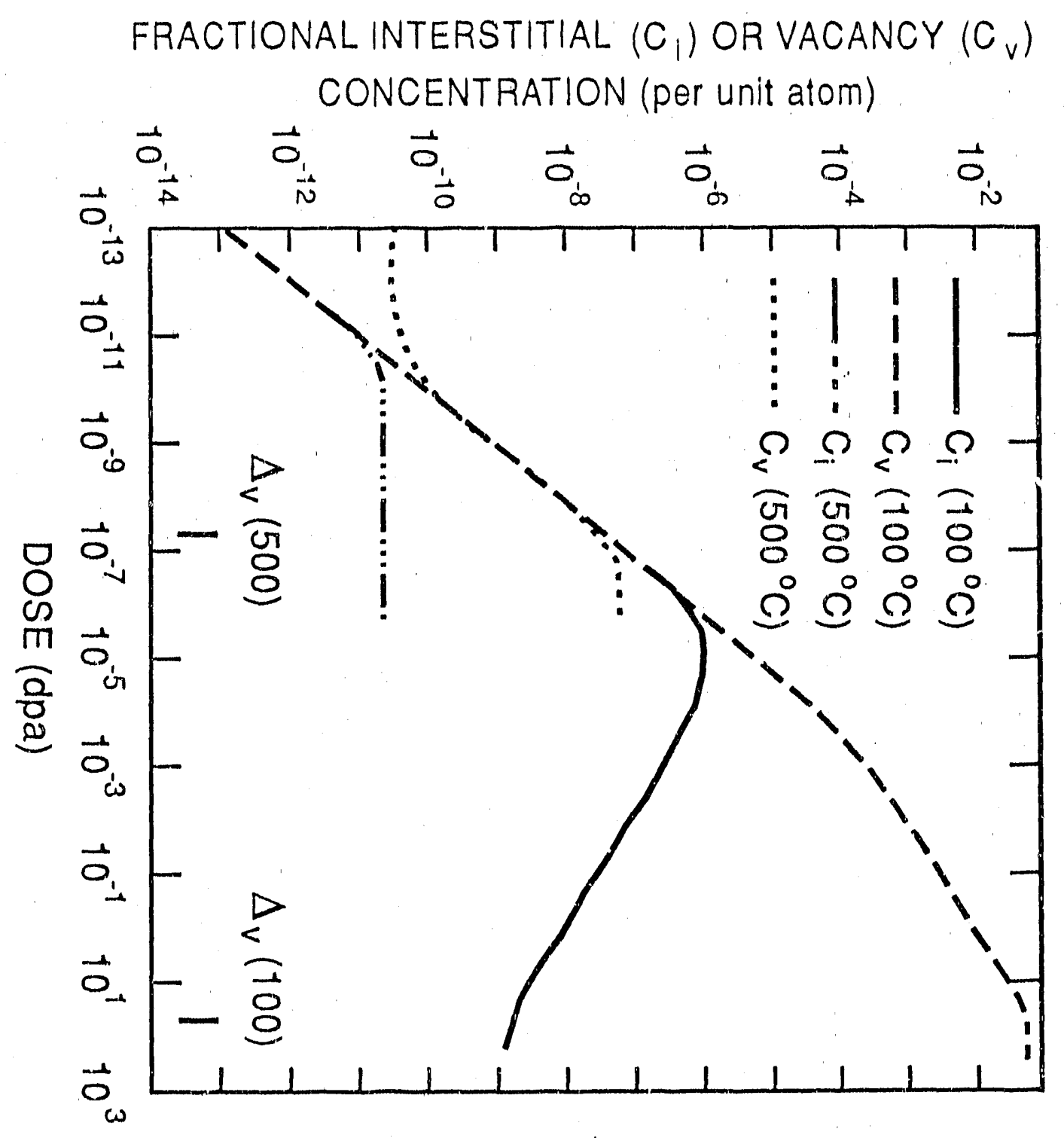

(a)

Figure 5. Dose dependence of the point defect concentrations (a) and the dislocation
climb velocity (b) at 100 and $500 \mathrm{C}$. (Stoller, Grossbeck and Mansur) 


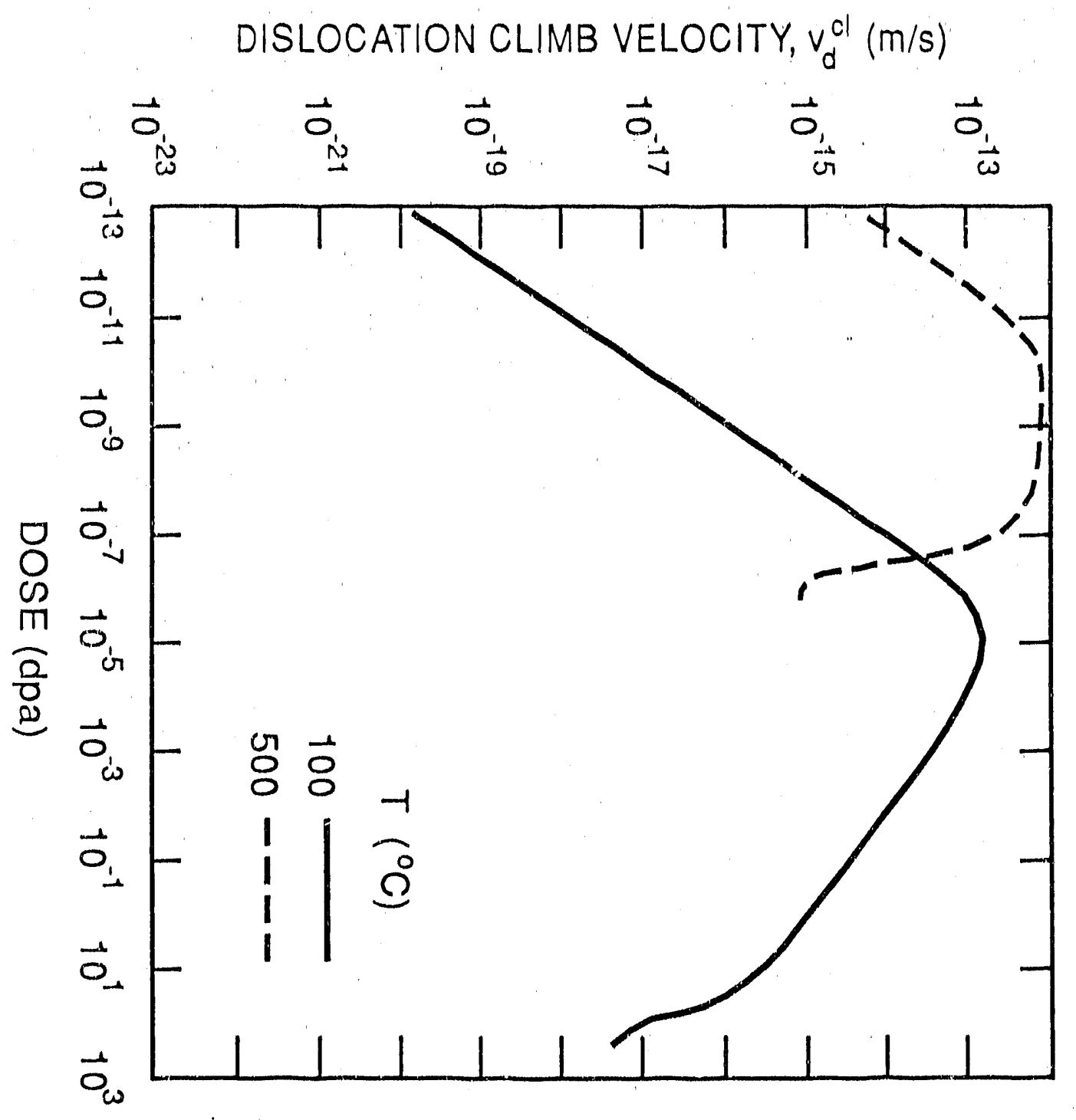

(b)

Figure 5. Dose dependence of the point defect concentrations (a) and the dislocation climb velocity (b) at 100 and $500 \mathrm{C}$.

(Stoller, Grossbeck and Mansur) 


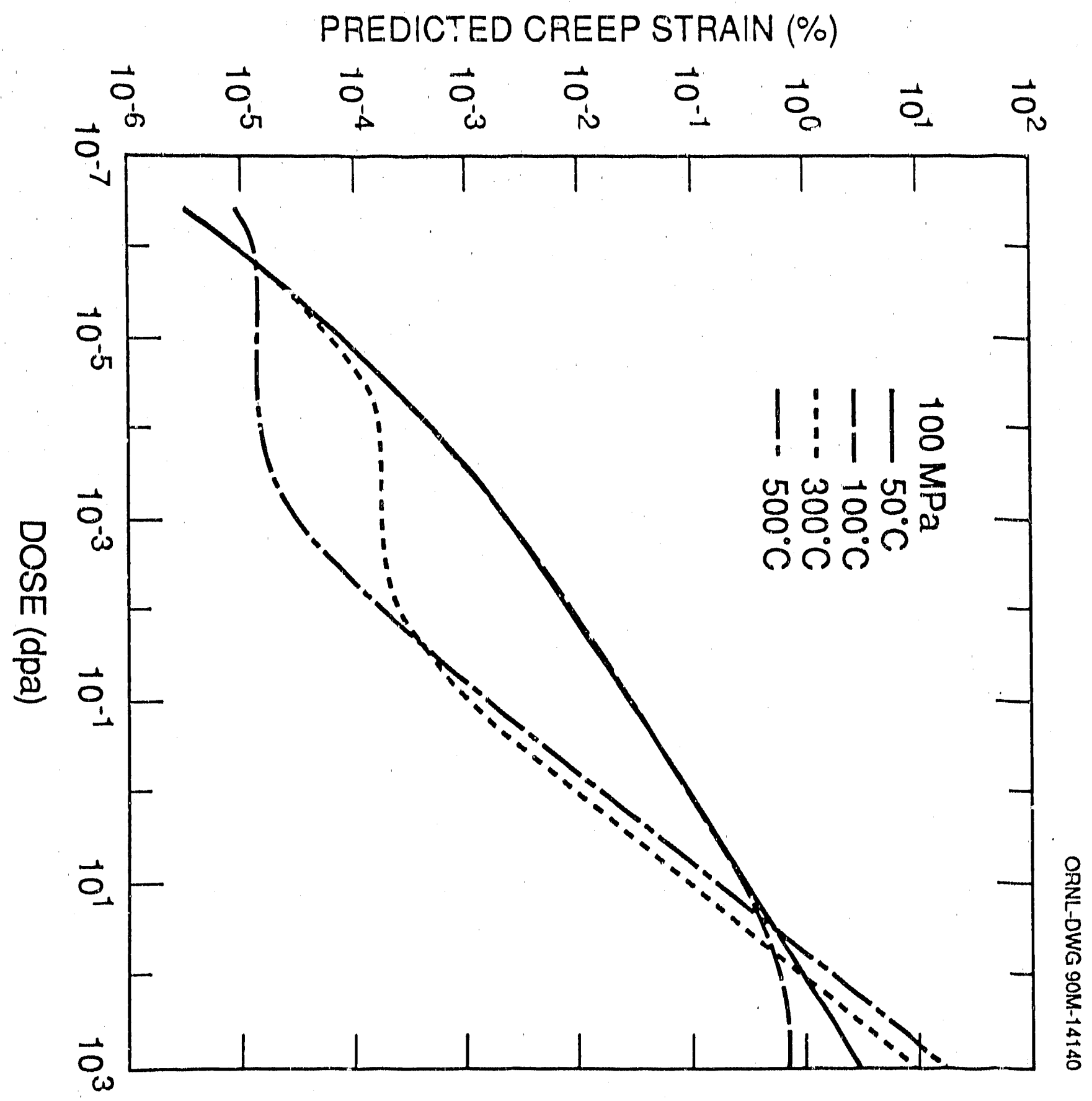

Figure 6. Predicted values of irradiation creep due to the climb-assisted dislocation glide mechanism. Results are shown as a function of dose with an applied
stress of $100 \mathrm{MPa}$ for irradiation temperatures of $50,100,300$, and $500 \mathrm{C}$. (Stoller, Grossbeck and Mansur) 


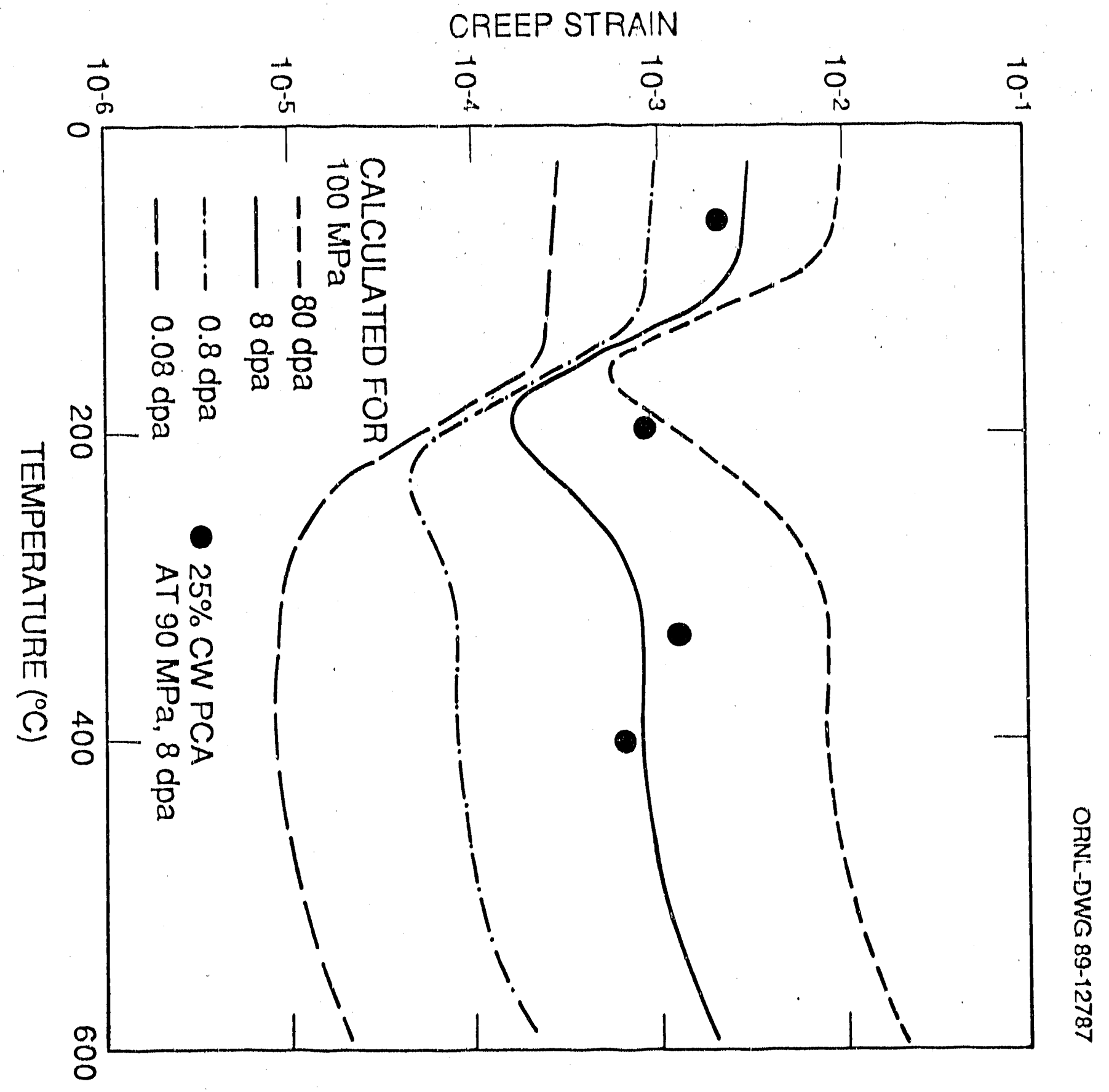

Figure 7. Temperature dependence of the predicted values of irradiation creep due to the climb-assisted dislocation glide mechanism. Results are shown for four doses with an applied stress of $100 \mathrm{MPa}$ and compared with measurements of $25 \%$ cold-worked PCA irradiated in the DRR-MFE-6.1/7.] experiment.

(Stoller, Grossbeck and Mansur) 


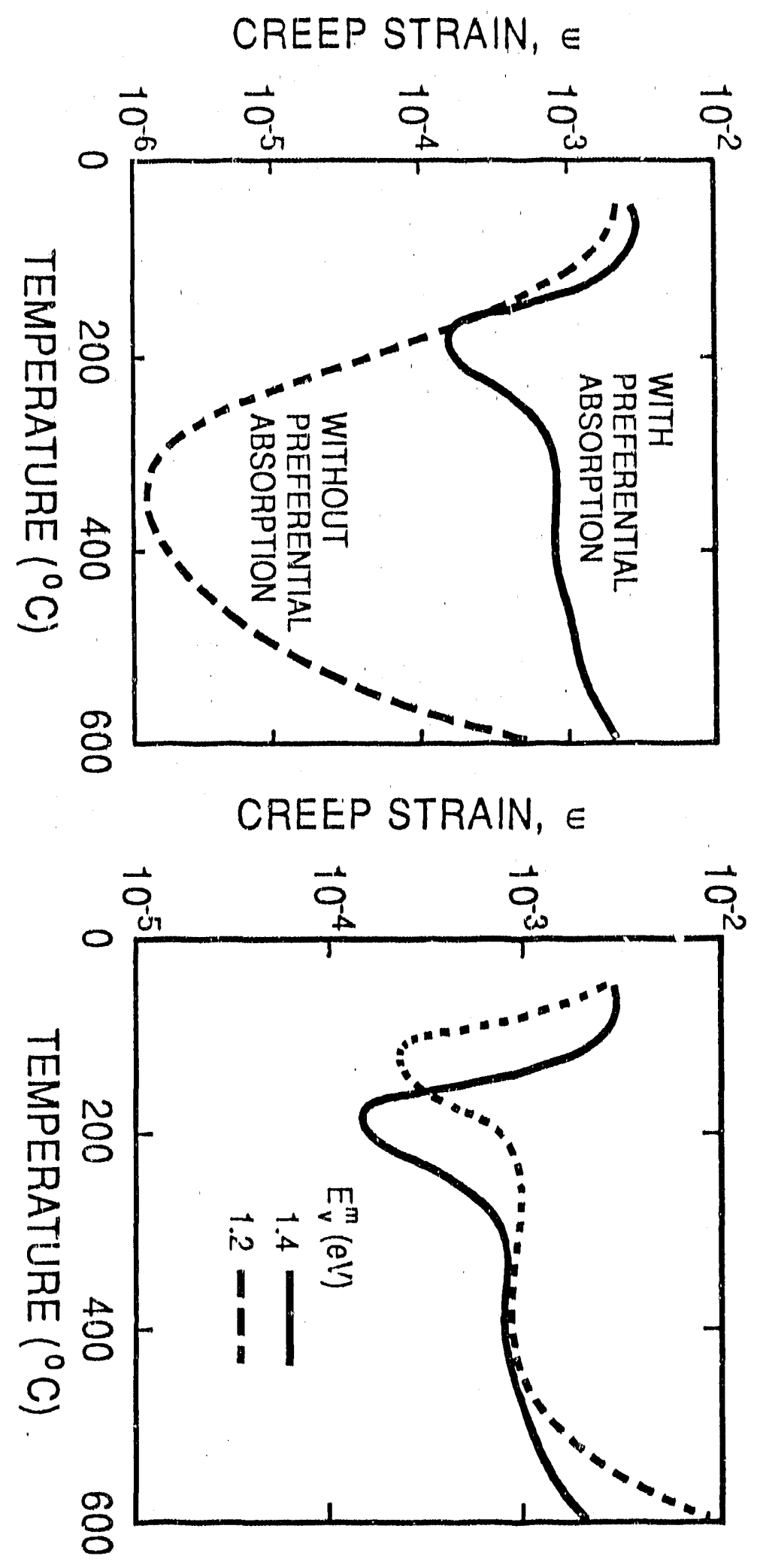

Figure 8. Dependence of the predicted irradiation creep at 8 dpa on model parameters. The solid lines in (a) and (b) indicate the behavior with base parameter sit discussed in the text. The broken line in (a) shows the predicted behavior if preferential interstitial absorption is not included in the model and the effect of varying the vacancy migration energy is shown in (b). (Stoller, Grossbeck and Mansur) 

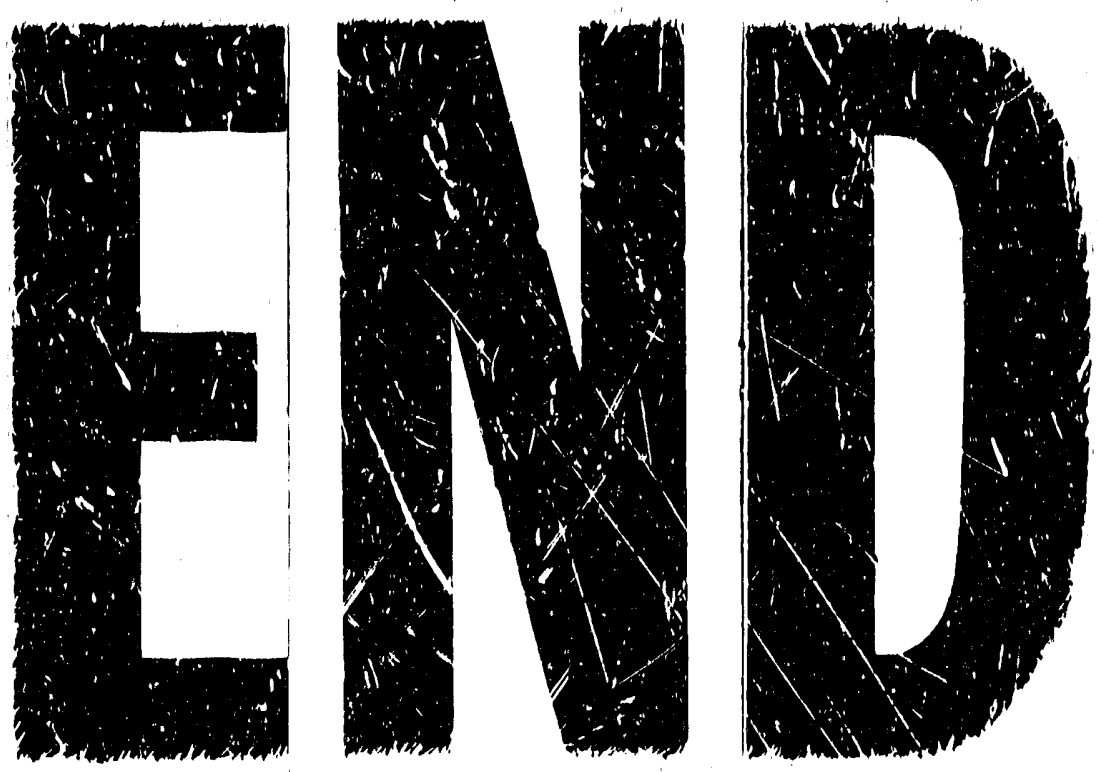

1
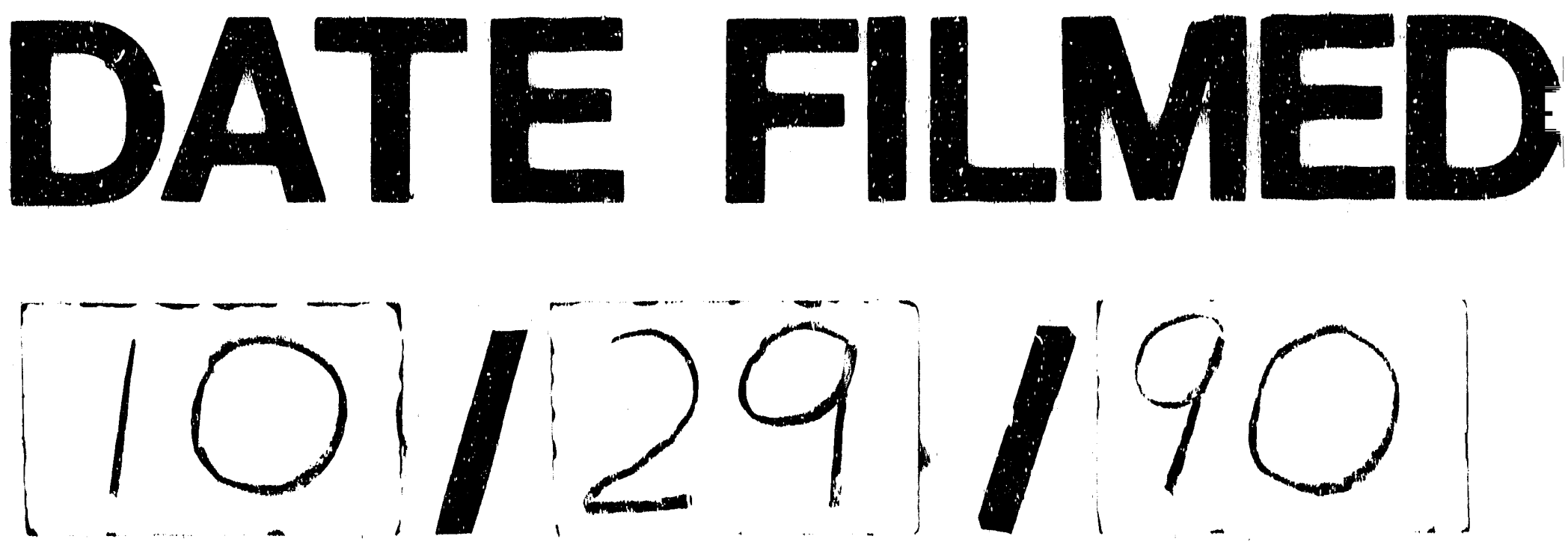

$-$ 
